\title{
Porta-enxertos e fixadores de enxerto para enxertia hipocotiledonar de maracujazeiro azedo
}

\author{
Rootstocks and tying materials for hipocotyledonar grafting of yellow passion fruit
}

\author{
Carlos Henrique Barbosa Santos ${ }^{\mathrm{I}}$ Alirio José da Cruz Neto ${ }^{\mathrm{I}}$ Taliane Leila Soares ${ }^{\mathrm{I}}$ \\ Eder Jorge de OliveiraII Onildo Nunes de Jesus ${ }^{I I}$ Eduardo Augusto Girardi ${ }^{I^{*}}$
}

RESUMO

\begin{abstract}
Avaliou-se a enxertia hipocotiledonar de maracujazeiro azedo em porta-enxertos de Passiflora alata, $\boldsymbol{P}$. edulis, $\boldsymbol{P}$. cincinnata e $\boldsymbol{P}$. gibertii utilizando-se, como fixadores para envolvimento da região da enxertia, fita adesiva tipo crepe, grampo metálico de cabelo e grampo de enxertia a mola. $O$ delineamento experimental foi em blocos ao acaso, em esquema fatorial $4 \times 3$ (porta-enxerto $x$ fixador), com 12 tratamentos, três repetições e oito plantas na parcela. Utilizou-se a enxertia hipocotiledonar pelo método de garfagem de topo em fenda cheia. Avaliaram-se diâmetro de caule, altura de planta e número de folhas do porta-enxerto no momento da enxertia, percentagem de sobrevivência da enxertia, diâmetro do caule, número de folhas e altura do enxerto aos 30, 60 e 90 dias após a enxertia. A sobrevivencia do enxerto de maracujazeiro azedo foi elevada, em geral, sendo equivalente para todos os porta-enxertos avaliados, demonstrando a eficiencia da técnica. $O$ uso dos fixadores de enxertia resultou em elevada percentagem de sobrevivência dos enxertos sem se verificarem diferenças entre os fixadores. Aos 90 dias após a enxertia, o maracujazeiro azedo, enxertado em $\boldsymbol{P}$. alata apresentou menor crescimento em relação àqueles enxertados em $\boldsymbol{P}$. edulis e P. gibertii.
\end{abstract}

Palavras-chave: Passiflora spp., crescimento vegetal, propagação. ABSTRACT

The hipocotyledonar grafting of yellow passion fruit was evaluated onto Passiflora alata, P. edulis, $\boldsymbol{P}$. cincinnata and $\boldsymbol{P}$. gibertii with masking tape, metallic hair clip and spring plastic graf clip as tying materials. Experimental design was randomized blocks in a factorial $4 \times 3$ (rootstock $x$ tying material) with 12 treatments, three replications and eight plants in the unit. The hipocotyledonar grafting method utilized was apical cleft grafting. Collected data included stem diameter, plant height and leaf number of rootstocks at grafting, and graft survival rate, stem diameter, leaf number and height 30,60 and 90 days after grafting.
Graft survival rate was high in general and equivalent among the evaluated rootstocks, indicating that apical cleft hipocotyledonar grafting was an efficient technique. All tying materials led to similar graft survival rates. Yellow passion fruit grafted onto $\boldsymbol{P}$. alata presented lower canopy growth in relation to plants grafted onto $\boldsymbol{P}$. edulis and $\boldsymbol{P}$. gibertii, 90 days after grafting.

Key words: Passiflora spp., plant growth, plant propagation.

\section{INTRODUÇÃO}

Apesar da importância econômica do maracujazeiro azedo (Passiflora edulis Sims.) para o Brasil, problemas fitossanitários comprometem a sua produtividade e longevidade, especialmente as doenças causadas por patógenos do solo, com destaque para a murcha causada pelo fungo Fusarium oxysporum $\mathrm{f}$. sp. passiflorae (LIBERATO \& COSTA, 2001; CHAVES et al., 2004).

$\mathrm{O}$ uso de mudas enxertadas em espécies resistentes tem sido relatado como método de controle para a fusariose do maracujazeiro (CHAVES et al., 2004). Várias espécies de passifloras silvestres como P. alata, P. caerulea L., P. gibertii N. E. Br., P. nitida Kunth, P. laurifolia L., P. setacea D.C., P. maliformis L. e $\boldsymbol{P}$. suberosa L. vêm apresentando resistência à murcha do fusário (MENEZES et al., 1994). A espécie silvestre $\boldsymbol{P}$. cincinnata Mast. ocorre com frequência em vários territórios da Bahia, mesmo em áreas com a presença de Fusarium spp. Entretanto, a utilização dessas espécies como porta-enxertos tem sido

${ }^{\mathrm{I}}$ Universidade Federal do Recôncavo da Bahia (UFRB), Cruz das Almas, BA, Brasil.

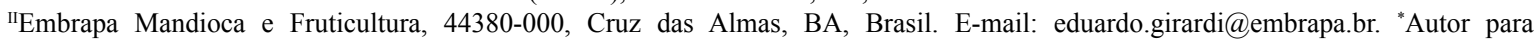
correspondência. 
dificultada pelas diferenças de diâmetro entre o portaenxerto e o enxerto de maracujazeiro azedo (CHAVES, 2004). Para contornar esta incompatibilidade dos diâmetros das partes envolvidas na enxertia, a técnica de enxertia hipocotiledonar é recomendada (LENZA et al., 2009; CORRÊA et al., 2010; NOGUEIRA FILHO et al., 2010; CAVICHIOLI et al., 2011a; NOGUEIRA FILHO et al., 2011; RONCATTO et al., 2011a; SANTOS et al., 2011).

$\mathrm{Na}$ enxertia, outro fator considerado importante é o tipo de fixador utilizado. A junção física entre o enxerto e porta-enxerto pode ser auxiliada pelo uso de vários materiais. A maioria dos trabalhos faz referência ao uso de fita adesiva tipo crepe e fita plástica transparente para a fixação do enxerto em porta-enxertos de maracujazeiro (RONCATTO et al., 2011b; NOGUEIRA FILHO et al., 2011; SANTOS et al., 2011). Contudo, a utilização de grampos de enxertia resulta em maior pegamento de enxertos e economia de mão-de-obra em plantas herbáceas, como cucurbitáceas e solanáceas (COSTA et al., 2001; LOPES \& GOTO, 2003). No maracujazeiro, até o momento, há poucas informações acerca do uso de grampos no pegamento da enxertia.

Assim, o objetivo deste trabalho foi avaliar o crescimento vegetativo e a sobrevivência de enxertos de maracujazeiro azedo enxertado em quatro porta-enxertos, utilizando-se três tipos de fixadores para envolvimento da região da enxertia.

\section{MATERIAL E MÉTODOS}

O experimento foi realizado em casa de vegetação da Embrapa Mandioca e Fruticultura, localizada em Cruz das Almas, BA (12 $12^{\circ} 39^{\prime} 25^{\prime}$ ' de latitude sul, $39^{\circ} 07^{\prime} 27^{\prime \prime}$ de longitude oeste, $222 \mathrm{~m}$ a.n.m.), entre julho e dezembro de 2011. O clima da região, segundo a classificação de Köppen, é do tipo BSa (com evapotranspiração potencial média anual maior do que a precipitação média anual, estação seca de verão, temperatura média superior a $22^{\circ} \mathrm{C}$ no mês mais quente do ano e umidade relativa média anual em torno de $80 \%$ ).

Todos os genótipos de maracujazeiro avaliados foram obtidos de sementes provenientes do Banco de Germoplasma de Maracujazeiro (BGM) da Embrapa Mandioca e Fruticultura, localizado em Cruz das Almas, BA. Como copa (enxerto), utilizou-se o maracujazeiro azedo Passiflora edulis 'GP09-03', selecionado pela Embrapa Mandioca e Fruticultura, por suas características agronômicas desejáveis para o mercado in natura, como frutos grandes, alta produtividade e elevado rendimento de polpa. Como porta-enxertos, avaliaram-se $\boldsymbol{P}$. alata Curtis (BGM 004), P. gibertii N.E. (BGM 008), $\boldsymbol{P}$. cincinnata Mast. (BGM 268) e P. edulis (GP09-03).

Logo após a colheita dos frutos e limpeza das sementes, realizou-se a semeadura em sacos de polietileno de dimensões $20 \times 12 \mathrm{~cm}$. O substrato utilizado na produção das mudas foi uma mistura de solo argiloso, esterco de curral curtido e vermiculita (3: 1: 1, $\mathrm{v}: \mathrm{v})$, apresentando os seguintes atributos químicos: $\mathrm{pH}$

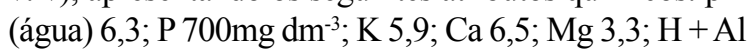
6,9; SB 16,9; T 23,2 $\mathrm{cmol}_{\mathrm{c}} \mathrm{dm}^{-3}$; V 70,0\%; M.O. 69,3g $\mathrm{kg}^{-1}$. Utilizou-se microaspersão intermitente, acionada por um controlador de tempo, com quatro irrigações diárias a $2 \mathrm{~L} \mathrm{~m}^{-2}$ durante $10 \mathrm{~min}$. $\mathrm{O}$ controle preventivo de antracnose foi efetuado via pulverizações quinzenais de difenoconazol $\left(20 \mathrm{~mL}\right.$ p.c. $\left.100 \mathrm{~L}^{-1}\right)$.

A enxertia foi realizada aos 55 dias após a emergência das plântulas, quando os porta-enxertos e os enxertos apresentaram quatro a cinco folhas definitivas. Nesta fase, avaliaram-se a altura (ALPE), realizada com auxílio de uma régua, medindo-se do cotilédone até o ápice da planta, o diâmetro do caule (DPE) na região hipocotiledonar, com auxílio de paquímetro digital e o número de folhas (NFPE) dos porta-enxertos.

$\mathrm{O}$ método de enxertia utilizado foi o hipocotiledonar por garfagem de topo em fenda cheia (Figura 1). Os porta-enxertos foram cortados rente e abaixo das folhas cotiledonares com uma tesoura. No local de corte, abriu-se uma fenda longitudinal de $1,0 \mathrm{~cm}$, com auxílio de um estilete. $\mathrm{Na}$ fenda aberta, foi inserido o enxerto, com cerca de $4 \mathrm{~cm}$ de comprimento, obtido a partir do ápice meristemático de plântulas provenientes de sementes de maracujazeiro 'GP0903'. A base do enxerto foi cortada em forma de cunha em bisel duplo e suas folhas foram podadas em 1/3 de sua área. Posteriormente, inseriu-se o enxerto no porta-enxerto cuidadosamente, de modo a coincidir os tecidos cambiais, sendo a região da enxertia protegida e fixada por fita adesiva tipo crepe, grampo metálico de cabelo ou grampo plástico de enxertia a mola.

Após a enxertia, as mudas foram colocadas em câmara úmida $(2,4 \mathrm{~m} \times 0,5 \mathrm{~m} \times 1,0 \mathrm{~m})$ confeccionada com plástico transparente de 150 micra, empregandose irrigação manual diariamente. Aos 30 dias após a enxertia (DAE), os fixadores de enxerto foram retirados, avaliando-se a percentagem de sobrevivência (SOB), calculada com base na contagem dos enxertos pegos, o diâmetro do caule do enxerto (DCE) (mm), estimado em cerca de $1 \mathrm{~cm}$ acima da região da enxertia com auxílio de um paquímetro digital, a altura do enxerto (ALE) (cm), mensurada com o auxílio de uma fita métrica, medindo-se a planta da região da enxertia até o ápice, e o número de folhas do enxerto (NFE). Aos 60 DAE, as 


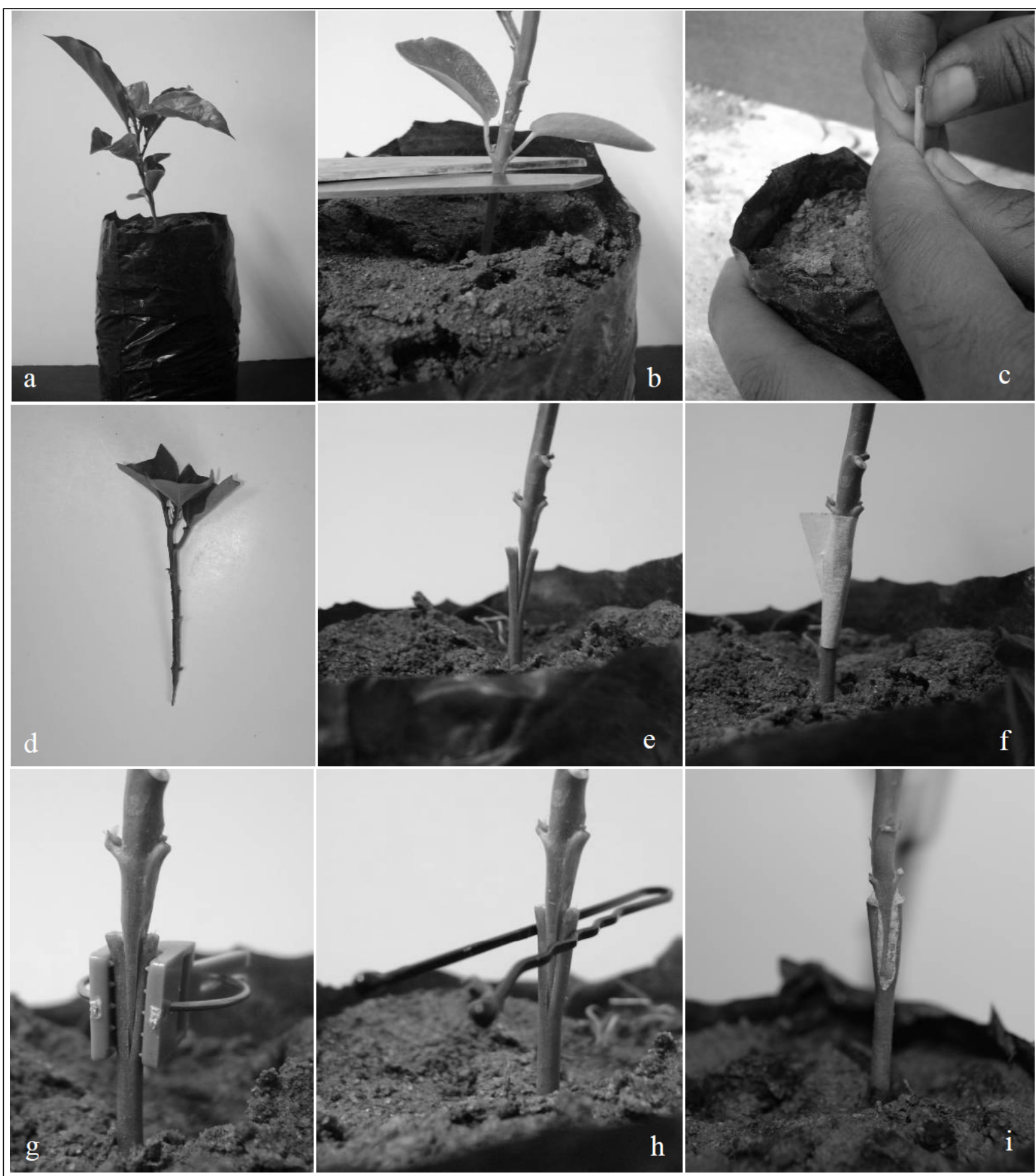

Figura 1 - Etapas da enxertia: a) Aspecto geral de mudas de Passiflora edulis utilizadas para fonte de enxerto e porta-enxerto; b) Corte transversal do porta-enxerto abaixo das folhas cotiledonares; c) Corte de fenda no caule do porta-enxerto com estilete; d-e) Aspecto do enxerto em forma de cunha e inserido no porta-enxerto; f) Região da enxertia protegida com fita adesiva tipo crepe; g) Região da enxertia protegida com grampo plástico de enxertia a mola; h) Região da enxertia protegida com grampo metálico de cabelo; e i) Cicatrização 90 dias após a enxertia.

mudas foram retiradas da câmara úmida e transferidas novamente para a casa de vegetação, sendo as mesmas avaliações descritas repetidas aos 60 e 90 DAE.

O delineamento experimental utilizado foi em blocos ao acaso, em esquema fatorial 4 × 3 (porta- enxerto x fixador do enxerto), com três repetições e oito plantas na parcela, sendo de seis plantas para $\boldsymbol{P}$. cincinnata em função da menor germinação de sementes. As avaliações aos 30,60 e 90 dias foram analisadas separadamente. Os resultados de 
percentagem de sobrevivência de enxertos foram previamente submetidos à transformação angular arco seno da raiz quadrada de x/100 para normalização e homogeneização das variâncias. Os resultados foram submetidos à análise de variância e as médias comparadas pelo teste de Tukey $(\mathrm{P} \leq 0,01)$.

\section{RESULTADOS E DISCUSSÃO}

No momento da enxertia, as plantas de $\boldsymbol{P}$. gibertii apresentaram maior altura, seguidas pelas plantas de $\boldsymbol{P}$. cincinnata, $\boldsymbol{P}$ edulis e $\boldsymbol{P}$. alata, respectivamente (Tabela 1). O maior e o menor diâmetro de caule foram observados em $\boldsymbol{P}$. edulis e $\boldsymbol{P}$. cincinnata, respectivamente. As plantas de $\boldsymbol{P}$. gibertii apresentaram menor número de folhas que $\boldsymbol{P}$. edulis, enquanto as demais espécies não diferiram quanto a esse atributo. CAVICHIOLI et al. (2009) também constataram menor altura de mudas da espécie $\boldsymbol{P}$. alata e maior altura em P. gibertii. Estes autores, contudo, observaram que plantas de $\boldsymbol{P}$. edulis e $\boldsymbol{P}$. gibertii apresentaram maior número de folhas em relação a $\boldsymbol{P}$. alata, diferindo do presente trabalho.

A percentagem de sobrevivência de enxertos não foi influenciada pelos porta-enxertos e fixadores de enxertos entre 30 e 90 DAE (Tabela 1). Da mesma maneira, não se observaram diferenças entre os tratamentos no que se refere ao número de folhas do enxerto neste período, sendo o incremento em número de folhas mais que o triplo (Tabela 2). Com relação ao diâmetro do caule de enxerto, não se observaram diferenças em função dos porta-enxertos avaliados 30 e 60 DAE, contudo, aos 90 DAE, o diâmetro de caule do enxerto de maracujazeiro azedo sobre $\boldsymbol{P}$. edulis e $\boldsymbol{P}$. gibertii foi superior ao de maracujazeiro azedo sobre $\boldsymbol{P}$. alata (Tabela 2).

Neste trabalho, a sobrevivência média de enxerto foi superior a $88 \%$ (Tabela 1 ), demonstrando boa compatibilidade entre a variedade copa e os porta-enxertos avaliados, assim como as condições de enxertia, a despeito do diâmetro de caule distinto entre os porta-enxertos no momento da enxertia. Plantas enxertadas em $\boldsymbol{P}$. edulis, P. gibertii, P. alata $\mathrm{e}$ $\boldsymbol{P}$. cincinnata apresentaram médias de sobrevivência de $100,97,8,95,7$ e $92,7 \%$, respectivamente, considerando-se os três períodos avaliados. Os resultados obtidos são corroborados pelos de CÔRREA et al. (2010), que observaram 100\% de pegamento na combinação de $\boldsymbol{P}$. edulis, enxertado em si mesmo e $98,8 \%$ para enxertia sobre $\boldsymbol{P}$. gibertii.

O bom desempenho da enxertia observado em $\boldsymbol{P}$. gibertii sugere elevada compatibilidade desta espécie com $\boldsymbol{P}$. edulis na fase de produção de mudas. Por outro lado, CÔRREA et al. (2010), trabalhando com porta-enxertos de $\boldsymbol{P}$. alata, $\boldsymbol{P}$. edulis e $\boldsymbol{P}$. gibertii, identificaram menor sobrevivência em plantas de $\boldsymbol{P}$. alata. Os autores atribuíram essa menor percentagem de sobrevivência ao menor diâmetro da copa e do

Tabela 1 - Análise de variância e médias de variáveis de crescimento de porta-enxertos de Passiflora spp. no momento da enxertia e porcentagem de sobrevivência de enxerto de maracujazeiro-azedo, submetido à enxertia hipocotiledonar em quatro portaenxertos de passifloras silvestres, utilizando-se três fixadores de enxerto, 30, 60 e 90 dias após a enxertia (DAE).

\begin{tabular}{|c|c|c|c|c|c|c|}
\hline Valor F & NFPE & $\mathrm{DPE}(\mathrm{mm})$ & $\operatorname{ALPE}(\mathrm{cm})$ & SOB $30 \mathrm{DAE}$ & SOB $60 \mathrm{DAE}$ & SOB $90 \mathrm{DAE}$ \\
\hline Porta-Enxerto (PE) & $3,81^{* *}$ & $34,51^{* *}$ & $108,68^{* *}$ & $0,64^{\mathrm{ns}}$ & $0,73^{\mathrm{ns}}$ & $1,35^{\mathrm{ns}}$ \\
\hline Fixadores (FE) & $1,66^{\mathrm{ns}}$ & $2,57^{\mathrm{ns}}$ & $0,95^{\mathrm{ns}}$ & $1,90^{\mathrm{ns}}$ & $0,93^{\mathrm{ns}}$ & $2,15^{\mathrm{ns}}$ \\
\hline PE $\times$ FE & $0,24^{\mathrm{ns}}$ & $0,31^{\mathrm{ns}}$ & $0,24^{\mathrm{ns}}$ & $0,64^{\mathrm{ns}}$ & $0,58^{\mathrm{ns}}$ & $0,50^{\mathrm{ns}}$ \\
\hline CV $(\%)$ & 11,00 & 9,65 & 19,16 & 6,13 & 8,89 & 9,86 \\
\hline Porta-enxerto & NFPE & DPE & ALPE & SOB $30 \mathrm{DAE}$ & SOB 60 DAE & SOB $90 \mathrm{DAE}$ \\
\hline P. alata & $7,22 \mathrm{ab}$ & $2,10 \mathrm{~b}$ & $3,20 \mathrm{~d}$ & $97 \mathrm{a}$ & $96 \mathrm{a}$ & $94 \mathrm{a}$ \\
\hline P. cincinnata & $7,88 \mathrm{ab}$ & $1,68 \mathrm{c}$ & $8,50 \mathrm{~b}$ & $96 \mathrm{a}$ & $94 \mathrm{a}$ & $88 \mathrm{a}$ \\
\hline P. edulis & $8,01 \mathrm{a}$ & $2,63 \mathrm{a}$ & $5,02 \mathrm{c}$ & $100 \mathrm{a}$ & $100 \mathrm{a}$ & $100 \mathrm{a}$ \\
\hline P. gibertii & $6,89 \mathrm{~b}$ & $1,99 \mathrm{~b}$ & $15,30 \mathrm{a}$ & $100 \mathrm{a}$ & $99 \mathrm{a}$ & $94 \mathrm{a}$ \\
\hline Fixador de enxertia & NFPE & DPE & ALPE & SOB $30 \mathrm{DAE}$ & SOB 60 DAE & SOB $90 \mathrm{DAE}$ \\
\hline G. de enxertia a mola & - & - & - & $100 \mathrm{a}$ & $100 \mathrm{a}$ & $98 \mathrm{a}$ \\
\hline G. metálico de cabelo & - & - & - & $97 \mathrm{a}$ & $97 \mathrm{a}$ & $92 \mathrm{a}$ \\
\hline Fita adesiva & - & - & - & $97 \mathrm{a}$ & $94 \mathrm{a}$ & 89 a \\
\hline
\end{tabular}

NFPE = número de folhas do porta-enxerto; DPE = diâmetro de caule do porta-enxerto; ALPE = altura do porta-enxerto; SOB = percentagem de sobrevivência de enxerto.

${ }^{* *}$ significativo $(\mathrm{P}<0,01),{ }^{\text {ns }}$ não significativo $(\mathrm{P}<0,01)$. Médias seguidas por letras diferentes na coluna diferem entre si pelo teste de Tukey $(\mathrm{P}<0,01)$.

- Dados não mensurados. 
Tabela 2 - Análise de variância e médias de variáveis de crescimento de maracujazeiro-azedo, submetido à enxertia hipocotiledonar em quatro porta-enxertos de passifloras silvestres, utilizando-se três fixadores de enxerto, 30, 60 e 90 dias após a enxertia (DAE).

\begin{tabular}{|c|c|c|c|c|c|c|c|c|}
\hline \multirow{2}{*}{ Valor F } & \multirow[t]{2}{*}{ NFE 30 DAE } & \multirow[t]{2}{*}{ NFE 60 DAE } & \multirow[t]{2}{*}{ NFE 90 DAE } & \multirow[t]{2}{*}{ DCE 30 DAE } & DCE 60 DAE & \multirow[t]{2}{*}{ DCE 90 DAE } & \multirow[t]{2}{*}{ ALE 60 DAE } & ALE 90 DAE \\
\hline & & & & & & & & \\
\hline Porta-enxerto (PE) & $1,10^{\mathrm{ns}}$ & $0,88^{\mathrm{ns}}$ & $0,64^{\mathrm{ns}}$ & $0,89^{\text {ns }}$ & $2,28^{\mathrm{ns}}$ & $4,45^{* *}$ & $10,13^{* *}$ & $9,45^{* *}$ \\
\hline Fixadores (FE) & $0,19^{\text {ns }}$ & $0,37^{\mathrm{ns}}$ & $0,02^{\mathrm{ns}}$ & $0,76^{\mathrm{ns}}$ & $1,41^{\mathrm{ns}}$ & $0,47^{\mathrm{ns}}$ & $3,22^{\mathrm{ns}}$ & $1,38^{\mathrm{ns}}$ \\
\hline PE x FE & $0,43^{\mathrm{ns}}$ & $0,44^{\mathrm{ns}}$ & $0,24^{\mathrm{ns}}$ & $0,60^{\mathrm{ns}}$ & $0,15^{\mathrm{ns}}$ & $0,37^{\mathrm{ns}}$ & $0,64^{\mathrm{ns}}$ & $0,92^{\mathrm{ns}}$ \\
\hline CV $(\%)$ & 29,41 & 13,63 & 29,91 & 9,30 & 9,85 & 8,79 & 12,50 & 16,90 \\
\hline Porta-enxerto & NFE 30 DAE & NFE 60 DAE & NFE 90 DAE & DCE $30 \mathrm{DAE}$ & DCE 60 DAE & DCE 90 DAE & ALE 60 DAE & ALE 90 DAE \\
\hline P. alata & $1,80 \mathrm{a}$ & $5,52 \mathrm{a}$ & $5,87 \mathrm{a}$ & $2,40 \mathrm{a}$ & $2,94 \mathrm{a}$ & $3,15 \mathrm{~b}$ & $15,93 \mathrm{~b}$ & $20,54 \mathrm{~b}$ \\
\hline$P$. cincinnata & $2,04 \mathrm{a}$ & $5,59 \mathrm{a}$ & $6,11 \mathrm{a}$ & $2,33 \mathrm{a}$ & $3,21 \mathrm{a}$ & $3,39 \mathrm{ab}$ & $20,07 \mathrm{a}$ & $25,40 \mathrm{ab}$ \\
\hline P. edulis & $2,05 \mathrm{a}$ & $6,05 \mathrm{a}$ & $6,90 \mathrm{a}$ & $2,49 \mathrm{a}$ & $3,32 \mathrm{a}$ & $3,62 \mathrm{a}$ & $21,30 \mathrm{a}$ & $28,92 \mathrm{a}$ \\
\hline P. gibertii & $1,65 \mathrm{a}$ & $5,86 \mathrm{a}$ & $6,82 \mathrm{a}$ & $2,42 \mathrm{a}$ & $3,13 \mathrm{a}$ & $3,58 \mathrm{a}$ & $21,60 \mathrm{a}$ & $31,01 \mathrm{a}$ \\
\hline Fixador de enxertia & NFE 30 DAE & NFE 60 DAE & NFE 90 DAE & DCE $30 \mathrm{DAE}$ & DCE 60 DAE & DCE 90 DAE & ALE 60 DAE & ALE 90 DAE \\
\hline G. de enxertia a mola & $1,82 \mathrm{a}$ & $5,75 \mathrm{a}$ & $6,40 \mathrm{a}$ & $2,47 \mathrm{a}$ & $3,13 \mathrm{a}$ & $3,50 \mathrm{a}$ & $21,2 \mathrm{a}$ & 28,1 a \\
\hline G. metálico de cabel & 01,96 a & $5,90 \mathrm{a}$ & $6,51 \mathrm{a}$ & $2,42 \mathrm{a}$ & $2,97 \mathrm{a}$ & $3,42 \mathrm{a}$ & $19,2 \mathrm{a}$ & $26,2 \mathrm{a}$ \\
\hline Fita adesiva & $1,88 \mathrm{a}$ & $5,63 \mathrm{a}$ & $6,36 \mathrm{a}$ & $2,33 \mathrm{a}$ & $3,10 \mathrm{a}$ & $3,40 \mathrm{a}$ & $18,8 \mathrm{a}$ & $25,1 \mathrm{a}$ \\
\hline
\end{tabular}

$\mathrm{NFE}=$ número de folhas do enxerto; $\mathrm{DCE}=$ diâmetro do caule do enxerto; $\mathrm{ALE}=$ altura do enxerto.

${ }^{* *}$ significativo $(\mathrm{P}<0,01)$, ${ }^{\text {ns }}$ não significativo $(\mathrm{P}<0,01)$. Médias seguidas por letras diferentes na coluna diferem entre si pelo teste de Tukey $(\mathrm{P}<0,01)$.

porta-enxerto alcançado nessa espécie, resultado similar ao observado neste estudo.

LIMA et al. (1999), comparando o desempenho dos porta-enxertos de $\boldsymbol{P}$. edulis, $\boldsymbol{P}$. giberti, $\boldsymbol{P}$. cincinnata, P. alata, $\boldsymbol{P}$. caerulea e $\boldsymbol{P}$. foetida, concluíram que as maiores percentagens de pegamento da enxertia de maracujazeiro azedo foram obtidas em $\boldsymbol{P}$. cincinnata (73\%) e $\boldsymbol{P}$. caerulea (74\%). Esses valores distintos e inferiores aos verificados no presente estudo podem estar relacionados a questões genéticas e varietais, ou mesmo às condições ambientais durante a enxertia. Segundo RONCATTO et al. (2011b), o pegamento da enxertia do maracujazeiro está relacionado à perfeita junção no ponto de enxertia, ocasionada pela uniformidade do material quanto ao diâmetro, e também pela adequada lignificação dos tecidos de enxerto e porta-enxerto.

A altura do enxerto não foi avaliada aos 30 DAE para não afetar a soldadura do enxerto. $P$. edulis, $\boldsymbol{P}$. gibertii e $\boldsymbol{P}$. cincinnata induziram maior altura de enxerto 60 DAE em relação a $\boldsymbol{P}$. alata (Tabela 2). Aos 90 DAE, com as mudas prontas para plantio no campo, mudas em $\boldsymbol{P}$. alata apresentaram altura igual a mudas em $\boldsymbol{P}$. cincinnata, mas inferior àquelas em $\boldsymbol{P}$. edulis e $\boldsymbol{P}$. gibertii. Resultados semelhantes foram relatados por CAVICHIOLI et al. (2011b).

Não foram verificadas diferenças significativas entre os fixadores de enxertia para quaisquer variáveis avaliadas, nem efeito de interação significativa entre porta-enxertos e fixadores de enxerto (Tabelas 1 e 2), evidenciando que todos os fixadores utilizados neste trabalho podem ser utilizados de forma eficiente na união entre a copa e o porta-enxerto de maracujazeiro. A maioria dos trabalhos anteriores utilizou fita adesiva tipo crepe para a enxertia hipocotiledonar de maracujazeiro (NOGUEIRA FILHO, et al., 2010; NOGUEIRA FILHO et al., 2011; RONCATTO et al., 2011a) e até mesmo fita plástica transparente (LENZA et al., 2009; CORRÊA et al., 2010; SANTOS et al., 2011). A avaliação de grampos como fixadores de enxerto na formação de mudas de maracujazeiro ainda é incipiente, embora esse tipo de fixador seja frequentemente utilizado na enxertia comercial de cucurbitáceas e solanáceas (COSTA et al., 2001; LOPES \& GOTO, 2003).

Entre as vantagens apontadas para a utilização de grampos em relação às fitas de enxertia, citam-se a praticidade, rapidez e facilidade de manuseio, demandando menor tempo para prender o enxerto no porta-enxerto, e a sua reutilização após desinfestação, reduzindo, assim, os custos da enxertia e o descarte de resíduos decorrentes das fitas plásticas. A multiplicação de maracujazeiro apresenta tendência de empregar métodos que envolvem propágulos com dimensões reduzidas (ALEXANDRE et al., 2013) e, assim, de difícil manipulação, sugerindo que o uso de grampos facilite as operações de enxertia. $\mathrm{O}$ uso de fitas implica amarrar e desamarrá-las após a enxertia, a fim de evitar danos ao crescimento do caule, o que demanda maior mão de obra e envolve ainda risco de deslocar o enxerto durante o manuseio. Neste trabalho, também não se observaram desgastes ou oxidação dos grampos avaliados após o uso em um ciclo de enxertia. 


\section{CONCLUSÃO}

A enxertia hipocotiledonar de maracujazeiro azedo em $\boldsymbol{P}$. edulis e $\boldsymbol{P}$. gibertii resulta em maior crescimento vegetativo de mudas em relação à enxertia em $\boldsymbol{P}$. alata. Houve alta taxa de sobrevivência de enxertos de maracujazeiro azedo enxertado nos porta-enxertos $\boldsymbol{P}$. edulis, $\boldsymbol{P}$. gibertii, $\boldsymbol{P}$. alata e $\boldsymbol{P}$. cincinnata, utilizando os três tipos de fixadores avaliados neste trabalho.

\section{AGRADECIMENTOS}

$\mathrm{O}$ primeiro e o segundo autores agradecem, respectivamente, à Coordenação de Aperfeiçoamento de Pessoal de Nível Superior (CAPES) e à Fundação de Amparo à Pesquisa do Estado da Bahia (FAPESB), pela concessão das bolsas de estudo.

\section{REFERÊNCIAS}

ALEXANDRE, R.S. et al. Metodologia de minienxertia em maracujazeiro. Revista Brasileira de Fruticultura, v.35, n.1, p.329-332, 2013. Disponível em: <http://www.scielo.br/pdf/rbf/ v35n1/40.pdf $>$. Acesso em: 20 jun. 2013. doi: 10.1590/S010029452013000100040

CAVICHIOLI, J.C. et al. Desenvolvimento e produtividade do maracujazeiro-amarelo enxertado em três porta-enxertos. Revista Brasileira de Fruticultura, v.33, n. 2, p.558-566, 2011a. Disponível em: <http://dx.doi.org/10.1590/S010029452011005000056>. Acesso em: 15 jul. 2013. doi: 10.1590/ S0100-29452011005000056.

CAVICHIOLI, J.C. et al. Uso de câmara úmida em enxertia hipocotiledonar de maracujazeiro-amarelo sobre três portaenxertos. Revista Brasileira de Fruticultura, v.31, n.2, p.532538, 2009. Disponível em: <http://dx.doi.org/10.1590/S010029452009000200030>. Acesso em: 15 jul. 2013. doi: 10.1590/ S0100-29452009000200030.

CAVICHIOLI, J.C. et al. Desenvolvimento, produtividade e sobrevivência de maracujazeiro-amarelo enxertado e cultivado em área com histórico de morte prematura de plantas. Revista Brasileira de Fruticultura, v.33, n.2, p.567-574, 2011b. Disponível em: $<$ http://dx.doi.org/10.1590/S0100-29452011005000075>. Acesso em: 20 jun. 2013. doi: 10.1590/S0100-29452011005000075.

CHAVES, R.C. et al. Enxertia de maracujazeiro-azedo em estacas herbáceas enraizadas de espécies de passifloras nativas. Revista Brasileira de Fruticultura, v.26, n.1, p.120-123, 2004. Disponível em: <http://dx.doi.org/10.1590/S010029452004000100033>. Acesso em: 16 jun. 2013. doi: 10.1590/ S0100-29452004000100033.

CORRÊA, L.S. et al. Uso de câmara úmida em enxertia convencional de maracujazeiro-amarelo sobre três portaenxertos. Revista Brasileira de Fruticultura, v.32, n.2. p.591598, 2010. Disponível em: <http://dx.doi.org/10.1590/S010029452010000200033>. Acesso em: 15 jul. 2013. doi: 10.1590/ S0100-29452010000200033.
COSTA, P.C. et al. Produção de pepino de plantas enxertadas cultivadas em soluções nutritivas com diferentes teores de potássio. Horticultura Brasileira, v.19, n.3, p.207-209, 2001. Disponível em: <http://dx.doi.org/10.1590/S0102-05362001000300010>. Acesso em: 15 jul. 2013. doi: 10.1590/S0102-05362001000300010.

LENZA, J.B. et al. Desenvolvimento de mudas de maracujazeiro propagadas por enxertia. Revista Brasileira de Fruticultura, v.31, n.4, p.1.135-1.140, 2009. Disponível em: <http://dx.doi. org/10.1590/S0100-29452009000400030>. Acesso em: 15 jul. 2013. doi: 10.1590/S0100-29452009000400030.

LIBERATO, J.R.; COSTA, H. Doenças fúngicas, bacterianas e fitonematóides. In: BRUCKNER, C.H.; PICANÇO, M.C. (Ed.). Maracujá: tecnologia de produção, pós-colheita, agroindústria, mercado. Porto Alegre: Cinco Continentes, 2001. p.243-245.

LIMA, A. de A. et al. Avaliação de porta-enxertos e tipos de enxertia para maracujá-amarelo. Revista Brasileira de Fruticultura, v.21, n. 3, p.318-321, 1999.

LOPES, M.C.; GOTO, R. Produção do híbrido Momotaro de tomateiro, em função da enxertia e do estádio das mudas no plantio. Horticultura Brasileira, v.21, n. 3, p.553-557, 2003. Disponível em: <http://dx.doi.org/10.1590/S010205362003000300028>. Acesso em: 20 jun. 2013. doi: 10.1590/ S0102-05362003000300028.

MENEZES, J.M.T. et al. Avaliação da taxa de pegamento de enxertos de maracujá-amarelo sobre espécies tolerantes à "morte prematura de plantas”. Científica, v.22, n.1, p.95-104, 1994.

NOGUEIRA FILHO, G.C. et al. Estudo da enxertia hipocotiledonar do maracujazeiro-amarelo sobre dois porta-enxertos, através de microscopia eletrônica de varredura. Revista Brasileira de Fruticultura, v.32, n.2, p.647-652, 2010. Disponível em: <http:// dx.doi.org/10.1590/S0100-29452010005000073>. Acesso em: 5 maio, 2013. doi: 10.1590/S0100-29452010005000073.

NOGUEIRA FILHO, G.C. et al. Produção de mudas de maracujazeiro-amarelo por enxertia hipocotiledonar sobre sete espécies de passifloras. Revista Brasileira de Fruticultura, v.33, n.1, p.237-245, 2011. Disponível em: < http://dx.doi.org/10.1590/ S0100-29452011005000027>. Acesso em: 3 maio, 2013. doi: $10.1590 / \mathrm{S} 0100-29452011005000027$.

RONCATTO, G. et al. Aspectos vegetativos de combinações copa/porta-enxerto em maracujazeiro. Revista Brasileira de Fruticultura, v.33, n.3, p.791-797, 2011a. Disponível em: <http:// dx.doi.org/10.1590/S0100-29452011000300013>. Acesso em: 6 abr. 2013. doi: 10.1590/S0100-29452011000300013.

RONCATTO, G. et al. Pegamento da enxertia em diferentes combinações de variedades e espécies utilizadas como copa e como porta-enxertos de maracujazeiro. Revista Brasileira de Fruticultura, v.33, n.3, p.948-953, 2011b. Disponível em: <http:// dx.doi.org/10.1590/S0100-29452011005000082>. Acesso em: 15 jun. 2013. doi: 10.1590/S0100-29452011005000082.

SANTOS, V.A. et al. Tipos de enxertia em diferentes idades de plantas de maracujazeiro. Revista Brasileira de Fruticultura, v.33, n.4, p.1359-1363, 2011. Disponível em: <http://dx.doi. org/10.1590/S0100-29452011000400039>. Acesso em: 8 jun. 2013. doi: 10.1590/S0100-9452011000400039. 